\title{
Effect Of E-OA-07 On Improving Joint Health And Mobility In Individuals With Knee Osteoarthritis: A Randomized, Double-Blind, Placebo-Controlled, Parallel Group Study
}

This article was published in the following Dove Press journal:

Journal of Pain Research

\author{
Shalini Srivastava $\mathbb{D}^{1}$ \\ Jayesh A Chaudhary ${ }^{2}$ \\ Robert N Girandola (iD ${ }^{3}$ \\ 'Department of Clinical Development, \\ Enovate Biolife, Mumbai, Maharashtra, \\ India; ${ }^{2}$ Vedic Lifesciences, Mumbai, \\ Maharashtra, India; ${ }^{3}$ Department of \\ Human Biology, University of Southern \\ California, Los Angeles, CA, USA
}

Aim: The aim of the present study was to evaluate the effect of E-OA-07 on individuals having osteoarthritis of the knee.

Background: Lanconone ${ }^{\circledR}$ (E-OA-07) is a widely marketed dietary supplement which has been previously studied in different clinical settings for managing chronic joint pain. This was a confirmatory study planned at a lowered dose regimen with the purpose of improving compliance and reducing consumer cost.

Methods: Male and female participants aged between 40 and 65 years, with history of joint pain for at least 3 years, were recruited. Knee joint dysfunction of grade II/III was radiographically characterized as per Kellgren-Lawrence system of classification. Enrolled participants were randomized to receive E-OA-07 at a dose of $1000 \mathrm{mg} /$ day or placebo over a period of 8 weeks. The primary efficacy parameter was assessment of change in Western Ontario and McMaster Universities Osteoarthritis Index (WOMAC) pain score. Whereas, the secondary parameters explored in the study included WOMAC subscales of stiffness and physical function, EQ-5D-5L questionnaire, systemic inflammatory marker (hs-CRP) and self-assessment of treatment satisfaction.

Results: At the end of 8 weeks, joint pain severity as per WOMAC was found to be significantly reduced in the E-OA-07 group as compared to placebo $(p<0.001)$. Similar improvement was observed in the subscales of stiffness and physical function which corresponds to significant improvement in the quality-of-life standards of E-OA-07 participants $(\mathrm{p}<0.001)$, reporting higher treatment satisfaction $(\mathrm{p}<0.001)$.

Conclusion: E-OA-07 at a dose of $1000 \mathrm{mg}$ /day was able to significantly reduce joint pain and thereby improve joint mobility in study participants. At the end of the study period, there was a clinically relevant change of $45.55 \%, 45.91 \%$ and $38.19 \%$ for pain, stiffness and physical function, respectively. Moving forward, studies could be planned for understanding the cartilage regenerative properties of E-OA-07.

Keywords: joint pain, joint inflammation, WOMAC, dietary supplement, osteoarthritis, Boswellia serrata

\section{Introduction}

In today's society of unparalleled competition and stress, staying active is a hallmark of success mainly determined by strong bones and healthy joints. Age-related musculoskeletal disorders are one of the major causes for morbidity resulting in a worldwide socio-economic burden. ${ }^{1}$ There have been substantial advancements in
Correspondence: Shalini Srivastava Enovate Biolife, 203, Morya Landmark, New Link Road, Andheri West, Mumbai, Maharashtra 400053, India

Tel +919619477885

Email shalini@enovatebiolife.com 
research as well as the number of therapies for degenerative joint disorders. However, a large extent of these are symptom oriented and are associated with unwanted adverse effects.

For instance, nonsteroidal anti-inflammatory drugs (NSAIDs), the cornerstone of pharmacotherapies, have been associated with life-threatening gastrointestinal adverse events such as bleeding and perforation. ${ }^{2}$ In 2015, the US Food and Drug Administration (FDA) took measures to strengthen the existing NSAIDs' label warnings, highlighting the increased risk of cardiovascular disorders with prolonged use of NSAIDs. ${ }^{3}$ Such events can significantly impact daily performance incurring increased health costs and physician visits. ${ }^{4}$ This emphasizes the need for therapeutic alternatives with proven safety profiles for chronic conditions of the joints.

The non-pharmacological treatments are viable therapeutic modalities for chronic conditions involving joint deterioration and inflammation. ${ }^{5}$ Physical activities are known to have a positive influence on patient's overall quality of life (QoL) whilst improving an array of physical limitations. ${ }^{6}$ There is also a growing body of evidence for certain foods and nutrients that can significantly improve the symptoms of chronic joint conditions. ${ }^{7,8}$ Although research exploring their impact has grown significantly, it has been associated with varying findings and limitations. For instance, majority of these require strict patient adherence for an extended period of time, sometimes for life. ${ }^{9}$ As their impact on disease progression is currently unknown, their usage has been limited or in combination with other conventional therapies.

Individuals who do not respond well to conventional medical therapy are turning towards complementary and alternative medications, such as natural or herbal supplements. The efficacy and safety of joint health-related natural supplements such as Zingiber officinale (ginger) ${ }^{10,11}$ and Curcuma longa (turmeric) ${ }^{12,13}$ have already been established in several clinical trials and are known to have potent anti-inflammatory and analgesic effects. Even a recent meta-analysis concluded that standardized extracts of turmeric have the potential to alleviate joint pain and inflammation in osteoarthritic patients. ${ }^{13}$ With emerging evidence and clinical support promoting the use of natural alternatives, Enovate Biolife developed E-OA-07, a novel blend of 7 herbal ingredients for managing the symptoms of knee osteoarthritis (OA).

The previous studies of E-OA-07 have yielded promising and encouraging results, promoting its safe use in chronic joint conditions. An earlier proof of concept study for E-OA-07 (2700 mg/day) established its efficacy and safety profile, particularly for knee OA with no serious adverse events being reported. ${ }^{14}$ In another study, E-OA-07 (1000 mg/day) was compared to ibuprofen, to provide a safe and equipotent alternative for alleviating joint pain. ${ }^{15}$ Results demonstrated that E-OA-07 provided clinically meaningful relief within $3 \mathrm{hrs}$ in activityinduced joint pain. Also, the quantum of relief experienced by participants was comparable to that of ibuprofen. With previous studies being indicative of the strong potency of E-OA-07, it encouraged us for conducting a confirmatory study in a different clinical setting. Therefore, the aim of the present study was to evaluate the efficacy and safety of E-OA-07 at a considerably lower dose with a view to improve treatment compliance and also for reducing cost borne by the consumer.

\section{Materials And Methods}

\section{Ethical Considerations}

The study was approved by an independent ethics committee - Aditya, registered with the Office for Human Research Protections in the US Department of Health and Human Services (IRB00006475). Written informed consents were voluntarily obtained from all study participants, and the study was registered on public clinical trials registry of US National Library of Medicine (clinicaltrials.gov; NCT03658369). The study was performed in compliance with the Helsinki Declaration and ICH-GCP guidelines.

\section{Participants}

Participants of either sex, between the age group of 40 and 65 years suffering from OA of the knee were enrolled in the present study. The parameter of joint dysfunction of knee OA was characterized radiographically as grade II/III as per the "Kellgren-Lawrence" classification system. ${ }^{16}$ Volunteers with body mass index (BMI) of $\geq 25$ and $\leq 29.9 \mathrm{~kg} / \mathrm{m}^{2}$ and knee joint pain of $\geq 60$ on a 100 -point Pain-VAS (Visual Analogue Scale) score were included in the present study. Participants with prior or ongoing medical conditions (e.g., concomitant systemic illness, psychiatric condition, alcoholism, drug abuse, physical inability, electrocardiogram or laboratory abnormalities, a history of surgery or major trauma to the joints) were not included in the present study. Also, participants presenting any signs or having history of systemic infection during screening were excluded from the clinical trial. Urine test 
for pregnancy was mandatory in females of childbearing potential. Individuals meeting the following criteria were included in the present 8 week randomized placebo-controlled study.

\section{Interventions}

The posology of E-OA-07 was determined through earlier conducted clinical trials. ${ }^{13,14}$ Based on the previous findings, the present study was designed to evaluate the efficacy of E-OA-07 at the lower dose of 1,000 $\mathrm{mg}$ in moderate-to-severe cases of knee OA. Lanconone ${ }^{\circledR}$ (Enovate Biolife, Wilmington DE, USA) is a buffcolored powder, rich in saponins, boswellic acids and other natural molecules purported to have analgesic and anti-inflammatory properties. It is a botanical compound based on 7 standardized herbal extracts, namely Shyonaka [Oroxylum indicum], Ashwagandha [Withania somnifera], Shunthi [Zingiber officinale], Guggul [Commiphora mukul], Chopchini [Smilax china], Rasana [Pluchea lanceolata], Shallaki [Boswellia serrata] [Table 1]. The "0" size capsule used for the study contained $500 \mathrm{mg}$ of E-OA-07 extract, and participants were instructed to take the 2 capsules after breakfast for the entire study period. Identical placebo capsules containing microcrystalline cellulose were manufactured and were matched for size, shape, color, texture, and packaging to preserve the blinding. The batch number of E-OA-07 used in this study was LN-AE-180801/02, and the control sample was retained with Enovate Biolife. Acetaminophen was allowed as a rescue medication at $500 \mathrm{mg}$ dose in case of severe pain but prohibited 48 hours prior to each assessment. The products were manufactured in a "Good Manufacturing Practice" certified unit and were stored as per the manufacturer's instructions throughout the study.

Table I Composition Of E-OA-07

\begin{tabular}{|l|l|l|l|}
\hline S. No. & Ingredients & Latin Name & Quantity (mg) \\
\hline 1 & Shyonak & Oroxylum indicum & 50 \\
2 & Ashwagandha & Withania somnifera & 70 \\
3 & Shunthi & Zingiber officinale & 30 \\
4 & Guggul & Commiphora mukul & 140 \\
5 & Chopchini & Smilax china & 50 \\
6 & Rasna & Pluchea lanceolate & 50 \\
7 & Shallaki & Boswellia serrata & 110 \\
& & & Total: $500 \mathrm{mg}$ \\
\hline
\end{tabular}

\section{Study Conduct}

This was an 8 week randomized, double-blind, placebocontrolled, parallel group study in adults reporting knee joint pain. The study was conducted under the supervision of qualified orthopedicians. The first study participant was enrolled in August 2018, and final participant completed the protocol designated end of treatment visit in February 2019. Prior to randomization, a 7-day placebo run-in period was completed by all participants for identifying placebo responders and also for ascertaining treatment compliance. Participants with no placebo response were randomized in blocks of four using Stats Direct software (version 3.2) to either receive E-OA-07 or placebo. Once randomized on baseline (day 0), participants were followed-up on days 7, 28 and 56, respectively.

The master randomization chart was password protected and maintained in the electronic trial master file. Appropriate blinding was maintained throughout the study, and the blinding codes were secured in tamperevident, sealed envelopes. Access was limited to authorized personnel on emergency basis as per Vedic Lifesciences standard operating procedures. The participants were also provided with a study diary to record study and non-study medications use during the course of the study. If any adverse events were experienced, the same was to be recorded by the participant in the study diary and communicated to the study investigator. Unused capsules were returned and checked by the trial coordinator for treatment compliance, who also checked the participant diary on scheduled visits to further verify IP compliance.

\section{Outcome Measures}

\section{Primary Outcome}

WOMAC is a self-administered validated instrument used widely in several clinical studies. The three WOMAC subscales comprise of 24 questions: Pain -5 , stiffness -2 , and physical function -17 , and each question is assessed on a Likert-based response rated from 0 to 4 points ( 0 indicates "no pain" and 4 "extreme pain"). Lower scores indicate improvement in participant's QoL. ${ }^{17}$

The primary outcome of the study was a reduction in WOMAC pain domain. The average response to 5 questions on a scale of 0-4 was calculated with a maximum score of 20. For evaluating the efficacy of E-OA-07, the change in the WOMAC pain values from day 0 to day 7 , 28 and 56 was compared to that of the placebo. 


\section{Secondary Outcome}

The secondary outcome for the study consisted of change in WOMAC subscales of stiffness (scale of $0-4$; averaged response for 2 questions) and physical function (scale of $0-4$; averaged response for 17 questions). ${ }^{17}$ Other measures performed included health-related quality of life (hr-QoL) as evaluated by a validated EQ-5D-5L questionnaire. It covers 5 domains - mobility, self-care, usual activities, pain/discomfort and anxiety/depression using 5 levels - no problems, slight problems, moderate problems, severe problems and extreme problems. ${ }^{18,19}$ Furthermore, treatment satisfaction was also assessed by a validated "Self-assessment of treatment (SAT)" questionnaire. The SAT questionnaire included five questions with 5-point response options for assessment of three areas, mainly pain relief, activity level and QoL. ${ }^{20}$ Change from day 0 to 56 was compared to that of the placebo for assessment of E-OA-07 efficacy in the above variables.

Recent research has shown that high levels of highsensitivity C-reactive protein (hs-CRP) are associated with severity of pain and disease progression in OA. ${ }^{21}$ Studies have also reported higher degree of joint degeneration in patients having increased levels of serum hs-CRP. ${ }^{22}$ Therefore, in the present clinical trial, the quantitative determination of hs-CRP was conducted to understand the effect of E-OA-07 in knee OA. Blood samples were collected from participants on baseline (day 0) and final visit (day 56) as per protocol and were centrifuged prior to performing the assay procedure. hsCRP was measured by particle-enhanced immunoturbidimetric methodology using commercially available reagents/kits (Roche Diagnostics $\mathrm{GmbH}$ ) on Cobas c 501 analyzer (Mannheim, Germany).

\section{Safety Assessments}

Vital signs (blood pressure and pulse rate), laboratory parameters (complete blood count, liver - Serum glutamic oxaloacetic transaminase (SGOT) and Serum glutamic pyruvic transaminase (SGPT) and kidney profile - creatinine), frequency and occurrence of adverse events or serious adverse events, and use of rescue medication were considered for safety evaluations. Physical examination and vital signs were measured on days $0,7,28$, and day 56. Blood samples were collected on days 0 and 56, and investigated using standard laboratory techniques by Suburban Diagnostics (Mumbai, India), accredited by "The College of American Pathologists" (CAP).

\section{Quality Assurance}

The study was conducted in compliance with the ICHGCP guidelines laid down in E6 (R1) as per pre-approved monitoring and auditing plan by a Vedic Lifesciences team, independent of the clinical operational team.

\section{Statistical Analysis}

A study of continuous response variables from matched pairs of study participants in two groups of 1:1 ratio was planned. Based on the available data, the difference in the response of matched pairs is normally distributed with a standard deviation of 4.34. Taking into consideration the true difference in the mean response of matched pairs as 2.38, a sample size of 60 participants was needed to be studied for rejecting the null hypothesis. The Type I error probability associated with this test is 0.05 with power at $80 \%$. To make up for some attrition during the trial period, a total of 72 participants were recruited and randomized in the ratio of 1:1. Data analysis was done for Per-Protocol (PP) population which was defined as the participants who completed the study without any major protocol deviations. Data normality was assessed using Shapiro-Wilk test. The baseline characteristics of the two groups were compared using independent $\mathrm{t}$-tests for continuous variables and Chi-square tests for categorical variables. A "Mixed model Analysis of Variance (ANOVA)" was used to assess the effect of interventions across multiple time points. Furthermore, statistical significance between the study groups was also evaluated using "Mann-Whitney $U$-tests" (non-parametric) and "Wilcoxon signed rank tests" (parametric) for drawing best statistical conclusions. A value of $\mathrm{p}<0.05$ was considered statistically significant, and data were expressed as mean \pm standard deviation.

Data processing, tabulation of descriptive statistics, and calculation of inferential statistics were performed using Statistical Package for the Social Sciences (SPSS, IBM ${ }^{\circledR}$ ) Python 3.0 (Armonk, New York, USA).

\section{Results}

A total of 78 potential participants were screened of which 72 were found eligible and were randomized in the ratio of 1:1. The enrolled population consisted of 36 participants each in E-OA-07 and placebo groups, respectively. As the study progressed, 5 participants from each group were lost to follow-up and withdrawn. The audit performed prior to data lock identified 18 participants, who were non-compliant to the study protocol and were hence excluded from 
final statistical analysis. The end of the study population consisted of 44 participants with 21 in the study group and 23 in the placebo group, respectively. The participant disposition for the study has been presented in Figure 1.

\section{Participant Demographics And Baseline Characteristics}

At baseline, the two groups were comparable in terms of demographic characteristics. The mean $( \pm \mathrm{SD})$ age of the participants in the E-OA-07 and placebo groups was 53.0 $( \pm 6.35)$ and $52.43( \pm 6.45)$ years, respectively. BMI values of the E-OA-07 and placebo groups were nearly similar $(27.15 \pm 1.46$ and $27.60 \pm 1.53)$. With respect to K\&L classification, 16 participants were of grade II severity and 5 were of grade III in the E-OA-07 group, whereas
14 were grade II and 9 were of grade III severity in the placebo group. A summarized description of participant demographics and baseline characteristics is provided in Table 2 .

\section{Effect Of E-OA-07 On WOMAC Pain Score}

At baseline, the mean \pm SD pain score for E-OA-07 and placebo groups was $14.95 \pm 1.72$ and $14.87 \pm 1.87$, respectively $(p=0.879)$. At the end of the study, E-OA-07 had a decreased mean score of $8.14 \pm 3.83$ $(\downarrow 6.8 \pm 3.6)$ and the placebo group score was $14.30 \pm$ $3.81(\downarrow 0.57 \pm 3.03)$ [Tables 3 and 4]. The difference between the values of two groups clearly shows that E-OA-07 significantly reduced pain from the beginning

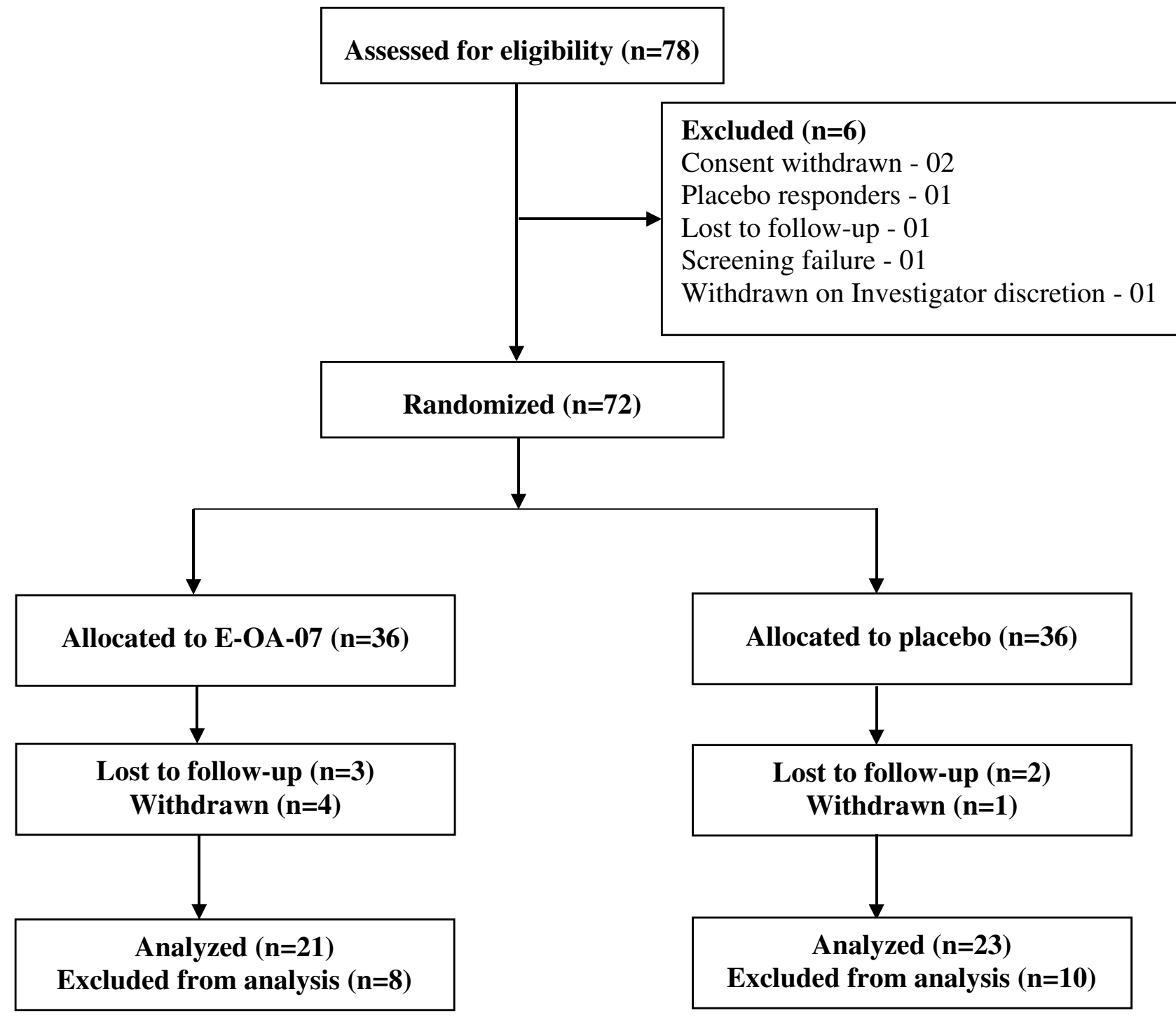

Figure I Participants Flow In The Study. 
Table 2 Participants Demographics And Baseline Characteristics

\begin{tabular}{|c|c|c|c|c|c|c|c|c|}
\hline & & \multicolumn{3}{|c|}{ Placebo $(n=23)$} & \multicolumn{3}{|c|}{ E-OA-07 (n=2I) } & \multirow[t]{3}{*}{ p value } \\
\hline & & \multirow[t]{2}{*}{ Mean (SD) } & \multicolumn{2}{|c|}{$95 \% \mathrm{Cl}$} & \multirow[t]{2}{*}{ Mean (SD) } & \multicolumn{2}{|c|}{$95 \% \mathrm{Cl}$} & \\
\hline & & & Min & Max & & Min & $\operatorname{Max}$ & \\
\hline \multicolumn{2}{|l|}{ Age (years) } & $52.43(6.45)$ & 41 & 62 & $53(6.35)$ & 40 & 63 & $0.77 \mid$ \\
\hline Gender (\%) & $\begin{array}{l}\text { Male } \\
\text { Female }\end{array}$ & $\begin{array}{l}4(17.40) \\
19(82.61)\end{array}$ & $\begin{array}{l}- \\
-\end{array}$ & - & $\begin{array}{l}\text { IO (47.62) } \\
\text { II (52.39) }\end{array}$ & - & - & $0.032^{*}$ \\
\hline \multicolumn{2}{|l|}{ BMI $\left(\mathrm{kg} / \mathrm{m}^{2}\right)$} & $27.60(1.53)$ & 26.94 & 28.27 & $27.15(1.46)$ & 26.48 & 27.82 & 0.322 \\
\hline \multicolumn{2}{|l|}{$\begin{array}{l}\text { Pulse Rate } \\
\text { (Per Minute) }\end{array}$} & $85.26(9.75)$ & 81.04 & 89.48 & $84.71(10.93)$ & 79.74 & 89.69 & 0.862 \\
\hline \multicolumn{2}{|c|}{ BP Systolic (mmHg) } & $123.39(6.77)$ & 120.46 & 126.32 & $123.24(7.01)$ & 120.05 & 126.43 & 0.942 \\
\hline \multicolumn{2}{|c|}{ BP Diastolic $(\mathrm{mmHg})$} & $82.43(7.45)$ & 79.21 & 85.66 & $80.43(6.42)$ & 77.50 & 83.35 & 0.346 \\
\hline \multicolumn{2}{|l|}{ FBS (mg/dl) } & $103.26(14.09)$ & 97.17 & 109.36 & $101.71(15.11)$ & 94.83 & 108.59 & 0.727 \\
\hline \multirow{2}{*}{\multicolumn{2}{|c|}{$\begin{array}{l}\text { KL Grades } \\
\text { of OA (n) }\end{array}$}} & Grade II - I4 & \multirow[t]{2}{*}{-} & & Grade II - 16 & \multirow[t]{2}{*}{-} & & \multirow[t]{2}{*}{$0.276 *$} \\
\hline & & Grade III - 9 & & & Grade III - 5 & & & \\
\hline \multicolumn{2}{|c|}{ VAS Pain Score } & $76.09(9.88)$ & 71.81 & 80.36 & 77.62 (II.79) & 72.25 & 82.99 & 0.642 \\
\hline \multicolumn{9}{|c|}{ Baseline Clinical Evaluation } \\
\hline \multicolumn{9}{|c|}{ WOMAC Scores } \\
\hline \multicolumn{2}{|l|}{ Pain } & $14.87(1.87)$ & 14.06 & 15.68 & I4.95 (I.72) & 14.17 & 15.73 & 0.879 \\
\hline \multicolumn{2}{|l|}{ Stiffness } & $05.17(1.61)$ & 4.48 & 5.87 & $05.38(1.02)$ & 4.92 & 5.85 & 0.618 \\
\hline \multicolumn{2}{|c|}{ Physical Function } & $61.83(8.70)$ & 58.07 & 65.59 & $63.71(6.86)$ & 60.59 & 66.84 & 0.431 \\
\hline \multicolumn{2}{|l|}{ Total } & $81.87(11.54)$ & 76.88 & 86.86 & $84.05(8.65)$ & 80.11 & 87.98 & 0.486 \\
\hline \multicolumn{2}{|c|}{ Total EQ-5D Score } & $|4.9|(2.92)$ & 13.65 & 16.18 & I5.86 (2.69) & 14.63 & 17.08 & 0.273 \\
\hline
\end{tabular}

Notes: $\mathrm{p}$, independent Student's $t$-test; ${ }^{*} \mathrm{p}$, Chi-square test.

Abbreviations: $n$, number of participants; BMI, body mass index; BP, blood pressure; FBS, fasting blood sugar; K\&L, Kellgren Lawrence; VAS, visual analogue scale; SD, standard deviation, $\mathrm{Cl}$, confidence interval; Min, minimum; Max, maximum.

of the $4^{\text {th }}$ week $(p=0.033)$ and was further responsible for the decreased pain scores post 8 weeks of administration $(\mathrm{p}<0.001)$ [Figure $2 \mathrm{~A}$ ].

Effect Of E-OA-07 On WOMAC Stiffness Score

At baseline, the mean \pm SD score for E-OA-07 and placebo groups was $5.38 \pm 1.02$ and $5.17 \pm 1.61$, respectively $(p=0.618)$. At the end of the study, stiffness score reduced significantly in the E-OA-07 to $2.91 \pm 1.51$, whereas the score increased to $5.44 \pm 1.62$ in the placebo group $(\mathrm{p}<$ 0.001) [Table 3 and Figure 2B]. At the end of 8 weeks, stiffness scores were significantly different in the E-OA-07 group as compared to placebo indicating significant reduction in stiffness subscale. Table 4 provides the absolute change in stiffness score for E-OA-07 and placebo groups, respectively.

\section{Effect Of E-OA-07 On WOMAC Physical}

\section{Function Score}

A comparative analysis of WOMAC physical function at baseline showed a mean \pm SD score of $63.71 \pm 6.86$ and $61.83 \pm 8.70(\mathrm{p}=0.431)$ for the E-OA-07 and placebo groups, respectively. At the end of the study, the physical function score was $39.38 \pm 13.66$ and $63.09 \pm 11.64$ $(\mathrm{p}<0.001)$, indicating significant improvement in the physical functioning of E-OA-07 study participants as compared to placebo group [Table 3 and Figure 2C]. The absolute change in physical function score for E-OA-07 and placebo groups is provided in Table 4 . 
Table 3 Visit Wise Scores Of WOMAC Pain, Stiffness, Physical Function And Total WOMAC Scores

\begin{tabular}{|c|c|c|c|c|c|c|c|c|}
\hline & \multirow[t]{3}{*}{ Visits } & \multicolumn{3}{|c|}{ Placebo $(n=23)$} & \multicolumn{3}{|c|}{ E-OA-07 (n=2I) } & \multirow[t]{3}{*}{ p value* } \\
\hline & & \multirow[t]{2}{*}{ Mean (SD) } & \multicolumn{2}{|c|}{$95 \% \mathrm{Cl}$} & \multirow[t]{2}{*}{ Mean (SD) } & \multicolumn{2}{|c|}{$95 \% \mathrm{Cl}$} & \\
\hline & & & Min & Max & & Min & Max & \\
\hline \multirow[t]{7}{*}{ Pain } & Day 0 & $14.87(1.87)$ & 14.06 & 15.68 & $14.95(1.72)$ & 14.17 & 15.73 & 0.879 \\
\hline & Day 7 & $14.87(2.26)$ & 13.89 & 15.85 & $14.86(2.22)$ & 13.89 & 15.87 & 0.985 \\
\hline & $\mathrm{P}$ value** & \multicolumn{3}{|l|}{0.952} & \multicolumn{3}{|l|}{$0.54 I$} & \\
\hline & Day 28 & | 4.35 (3.04) & 13.03 & 15.66 & $12.38(2.85)$ & 11.08 & 13.68 & 0.033 \\
\hline & $\mathrm{P}$ value** & \multicolumn{3}{|l|}{0.320} & \multicolumn{3}{|l|}{0.003} & \\
\hline & Day 56 & $14.30(3.81)$ & 12.66 & 15.95 & $8.14(3.84)$ & 6.40 & 9.89 & $<0.001$ \\
\hline & $\mathrm{P}$ value** & 0.408 & & & $<0.001$ & & & \\
\hline \multirow[t]{7}{*}{ Stiffness } & Day 0 & $5.17(1.61)$ & 4.48 & 5.87 & $5.38(1.02)$ & 4.92 & 5.85 & 0.618 \\
\hline & Day 7 & $5.39(1.37)$ & 4.80 & 5.99 & $5.33(1.16)$ & 4.81 & 5.86 & $0.88 I$ \\
\hline & $\mathrm{P}$ value** & \multicolumn{3}{|l|}{0.305} & \multicolumn{3}{|l|}{0.480} & \\
\hline & Day 28 & $5.04(1.19)$ & 4.53 & 5.56 & $4.52(1.37)$ & 3.90 & 5.15 & 0.184 \\
\hline & $\mathrm{P}$ value** & \multicolumn{3}{|l|}{0.609} & \multicolumn{3}{|l|}{0.009} & \\
\hline & Day 56 & $5.44(1.62)$ & 4.74 & 6.14 & $2.91(1.51)$ & 2.22 & 3.59 & $<0.001$ \\
\hline & $\mathrm{P}$ value** & 0.487 & & & $<0.001$ & & & \\
\hline \multirow[t]{7}{*}{ Physical Function } & Day 0 & $61.83(8.70)$ & 58.07 & 65.59 & 63.71 (6.86) & 60.59 & 66.84 & 0.431 \\
\hline & Day 7 & $62.44(7.48)$ & 59.20 & 65.67 & $63.67(8.14)$ & 59.96 & 67.37 & 0.603 \\
\hline & $\mathrm{P}$ value** & \multicolumn{3}{|l|}{0.602} & \multicolumn{3}{|l|}{1.000} & \\
\hline & Day 28 & 61.04 (9.08) & 57.12 & 64.97 & $54.76(10.61)$ & 49.93 & 59.59 & 0.040 \\
\hline & $\mathrm{P}$ value** & \multicolumn{3}{|l|}{0.519} & \multicolumn{3}{|l|}{0.001} & \\
\hline & Day 56 & 63.09 (11.64) & 58.05 & 68.12 & $39.38(13.66)$ & 33.16 & 45.60 & $<0.001$ \\
\hline & $P$ value** & \multicolumn{3}{|l|}{0.603} & \multicolumn{3}{|l|}{$<0.001$} & \\
\hline \multirow[t]{7}{*}{ Total WOMAC } & Day 0 & 81.87 (11.54) & 76.88 & 86.86 & $84.05(8.65)$ & 80.11 & 87.98 & 0.486 \\
\hline & Day 7 & $82.70(10.27)$ & 78.26 & 87.14 & $83.86(10.72)$ & 78.98 & 88.74 & 0.715 \\
\hline & $\mathrm{P}$ value** & \multicolumn{3}{|l|}{0.641} & \multicolumn{3}{|l|}{0.599} & \\
\hline & Day 28 & 80.44 (12.87) & 74.87 & 86.00 & 71.67 (14.40) & 65.11 & 78.22 & 0.039 \\
\hline & $\mathrm{P}$ value** & \multicolumn{3}{|l|}{0.495} & 0.001 & & & \\
\hline & Day 56 & $82.83(16.77)$ & 75.57 & 90.08 & $50.43(18.57)$ & 41.97 & 58.88 & $<0.001$ \\
\hline & $\mathrm{P}$ value** & $0.87 \mid$ & & & $<0.001$ & & & \\
\hline
\end{tabular}

Notes: *P, Mann-Whitney $U$-test; **Wilcoxon signed rank test.

Abbreviations: $\mathrm{n}$, number of participants; SD, standard deviation; $\mathrm{Cl}$, confidence interval; Min, minimum; Max, maximum.

Effect OfE-OA-07 On Total WOMAC Score

The total WOMAC score was significantly improved in the E-OA-07 group as compared to placebo. At baseline, total WOMAC score for E-OA-07 and placebo groups was reported to be $84.05 \pm 8.65$ and $81.87 \pm 11.54$, respectively $(\mathrm{p}=0.486)$. At the end of study, the scores were decreased significantly in the E-OA-07 group to $50.43 \pm 18.57$, whereas the score was $82.83 \pm 16.77$ in the placebo 
Table 4 Change In WOMAC Subscale Of Pain, Stiffness, Physical Function And Total WOMAC Scores

\begin{tabular}{|c|c|c|c|c|c|c|c|}
\hline \multirow[t]{3}{*}{ Visit } & \multicolumn{3}{|c|}{ Placebo $(n=23)$} & \multicolumn{3}{|c|}{ E-OA-07 $(n=21)$} & \multirow[t]{3}{*}{ p value } \\
\hline & \multirow[t]{2}{*}{ Mean (SD) } & \multicolumn{2}{|l|}{$95 \% \mathrm{Cl}$} & \multirow[t]{2}{*}{ Mean (SD) } & \multicolumn{2}{|l|}{$95 \% \mathrm{Cl}$} & \\
\hline & & Min & Max & & Min & Max & \\
\hline \multicolumn{8}{|l|}{ Pain } \\
\hline Change (Day 7) & $0.00(1.09)$ & -0.47 & 0.47 & $-0.10(1.41)$ & -0.737 & 0.547 & 0.802 \\
\hline Change (Day 28) & $-0.52(2.35)$ & -1.54 & 0.50 & $-2.57(2.66)$ & -3.781 & -1.362 & 0.010 \\
\hline Change (Day 56) & $-0.57(3.03)$ & -1.87 & 0.74 & $-6.81(3.60)$ & -8.448 & -5.171 & $<0.001$ \\
\hline \multicolumn{8}{|l|}{ Stiffness } \\
\hline Change (Day 7) & $0.22(0.95)$ & -0.19 & 0.63 & $-0.05(0.8 \mathrm{I})$ & -0.414 & 0.319 & 0.327 \\
\hline Change (Day 28) & $-0.13(1.39)$ & -0.73 & 0.47 & $-0.86(1.20)$ & -1.401 & -0.313 & 0.071 \\
\hline Change (Day 56) & $0.26(1.82)$ & -0.52 & 1.05 & $-2.48(1.37)$ & -3.097 & -1.855 & $<0.001$ \\
\hline \multicolumn{8}{|l|}{ Physical function } \\
\hline Change (Day 7) & $0.61(5.48)$ & -1.76 & 2.98 & $-0.05(3.54)$ & -1.66 & 1.57 & 0.643 \\
\hline Change (Day 28) & $-0.78(8.45)$ & -4.44 & 2.87 & $-8.95(8.87)$ & -12.99 & -4.91 & 0.003 \\
\hline Change (Day 56) & $1.26(12.10)$ & -3.97 & 6.49 & $-24.33(13.80)$ & -30.62 & -18.05 & $<0.001$ \\
\hline \multicolumn{8}{|l|}{ Total WOMAC } \\
\hline Change (Day 7) & $0.83(6.56)$ & -2.009 & 3.661 & $-0.19(4.94)$ & -2.437 & 2.06 & 0.567 \\
\hline Change (Day 28) & -1.44 (II.27) & -6.306 & 3.436 & $-12.38(11.70)$ & -17.708 & -7.05 & 0.003 \\
\hline Change (Day 56) & $0.96(16.26)$ & -6.073 & 7.986 & $-33.62(17.94)$ & -41.785 & -25.45 & $<0.001$ \\
\hline
\end{tabular}

Note: *P, mixed analysis of variance.

Abbreviations: $\mathrm{n}$, number of participants; SD, standard deviation; $\mathrm{Cl}$, confidence interval; Min, minimum; Max, maximum.

group; $\mathrm{p}<0.001$. The difference of scores as compared from baseline implies that there was a significant improvement in E-OA-07 participants at the end of 8 weeks [Table 3 and Figure 2D]. Table 4 provides the absolute change in total WOMAC score for E-OA-07 and placebo groups, respectively.

\section{Effect Of E-OA-07 On European Quality Of Life-5 Dimension Score}

At the end of 8 weeks, trend of reduction in the E-OA-07 group of participants was similar in each of the 5 domains of the EQ-5D questionnaire (mobility; self-care; daily activities; pain/discomfort; and depression $-\mathrm{p}<0.001$ ). At the baseline visit, the total EQ-5D score for E-OA-07 and placebo groups was $15.86 \pm 2.69$ and $14.91 \pm 2.92$, respectively. At the end of the study, total score for E-OA-07 group was significantly reduced to $8.57 \pm 3.14$ and was comparably different from the placebo group score of $15.96 \pm 3.72 ; \mathrm{p}<0.001$ [Table 5 and Figure 3].

\section{Effect Of E-OA-07 On Treatment-Related}

\section{Satisfaction}

At the end of the study, overall SAT scores of E-OA-07 and placebo groups were $20.05 \pm 4.60$ and $11.30 \pm 4.62$, respectively, [Table 6]. The difference between the efficacy assessments of two groups was statistically significant ( $p<0.001)$, and participants were to a greater extent satisfied in the E-OA-07 group as compared to placebo.

\section{Effect Of E-OA-07 On High-Sensitivity C-Reactive Protein}

At baseline, both groups had nearly similar levels of hs-CRP. The E-OA-07 value was $3.79 \pm 3.43$, and for placebo, it was $3.18 \pm 2.87$. The hs-CRP levels did not show any significant improvements in either of the groups as the hs-CRP values of the placebo group were $4.65 \pm 6.09$ and E-OA-07 were 3.86 \pm 4.00 , respectively. Though the values of placebo group were increased, the change between the groups was nonsignificant [Table 7].

\section{Rescue Medication And Compliance}

When compared from day 0 to 28 , the acetaminophen usage in E-OA-07 was $9.38 \pm 8.41$ and placebo group was $10.35 \pm$ 7.59 , respectively. However, from day 28 to 56 , it reduced to $4.14 \pm 4.45$ in the E-OA-07 group as compared to $8.83 \pm 10.59$ in the placebo group. Also, the compliance recorded in the E-OA-07 group of participants was more than $90 \%$ in the 


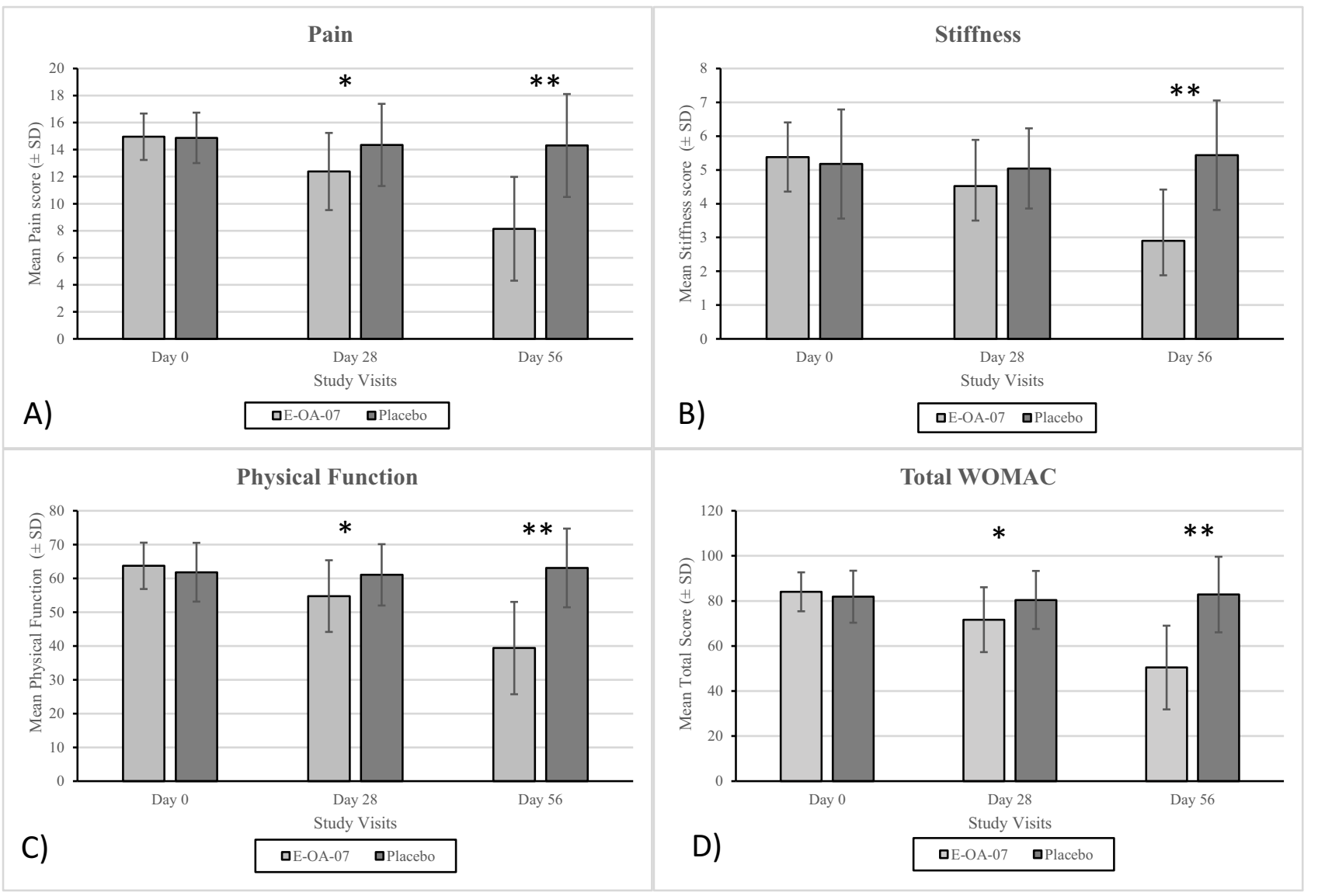

Figure 2 Changes in WOMAC subscale mean score (A) pain, (B) stiffness, (C) physical function, and (D) total WOMAC. Data are represented as Mean \pm SD. *p<0.05 and **p $<0.001$.

analyzed population. This shows that participants in the E-OA-07 group experienced a greater degree of relief as compared to the comparator (placebo) group in the course of the study duration.

\section{Safety Evaluations}

Physical examination and vital signs were normal throughout the study, and there were no clinically significant abnormal findings in either of the study groups [Table 7]. The hemoglobin levels, RBC Count, WBC Count, and biochemical evaluations of SGOT and SGPT were in the range of normal laboratory reference values with no clinically significant observations in either of the groups. Overall, E-OA-07 was found to be safe and was well tolerated by the study participants [Table 8].

\section{Adverse Events}

During the course of the study, there were no serious/ severe adverse events reported in either of the study groups.

\section{Discussion}

In the last few decades, drug discovery from plant-based extracts has been a primary area of research for scientists and academicians alike. ${ }^{23}$ The importance of nutraceuticals for the management of musculoskeletal disorders is now being recognized globally in terms of alleviating health-care standards and managing health-care costs. It is now evident from a number of clinical trials that nutraceuticals can be envisioned as one of the missing blocks for prevention and treatment of chronic disorders, such as OA. ${ }^{24-26}$ In the present study, we evaluated E-OA-07, a natural alternative for reducing joint pain and improving physical function, specifically in weight-bearing joints deteriorated by degenerative conditions.

Nutritional supplements are generally touted as safer alternatives to pharmacotherapies. However, due to their slow onset of action, they do not serve as a preferred choice for treating chronic disorders. A study by Majeed et al assessed the safety and efficacy of Boswellia serrata extract in the management of knee OA. The extract demonstrated a 
Table 5 Effect Of E-OA-07 And Placebo On EQ-5D-5L Scores

\begin{tabular}{|c|c|c|c|c|c|c|c|c|}
\hline \multirow[t]{3}{*}{ Domains } & \multirow[t]{3}{*}{ Visit } & \multicolumn{3}{|c|}{ Placebo $(n=23)$} & \multicolumn{3}{|c|}{ E-OA-07 (n=2I) } & \multirow[t]{3}{*}{ p value* } \\
\hline & & \multirow[t]{2}{*}{ Mean (SD) } & \multicolumn{2}{|c|}{$95 \% \mathrm{Cl}$} & \multirow[t]{2}{*}{ Mean (SD) } & \multicolumn{2}{|c|}{$95 \% \mathrm{Cl}$} & \\
\hline & & & Min & $\operatorname{Max}$ & & Min & $\operatorname{Max}$ & \\
\hline \multirow[t]{3}{*}{ Mobility } & Day 0 & $3.09(0.67)$ & 2.80 & 3.38 & $3.24(0.70)$ & 2.92 & 3.56 & 0.324 \\
\hline & Day 56 & $3.52(0.99)$ & 3.09 & 3.95 & $1.67(0.73)$ & 1.33 & 2.00 & $<0.001$ \\
\hline & $\mathrm{P}^{* *}$ & \multicolumn{3}{|l|}{0.008} & \multicolumn{3}{|l|}{$<0.001$} & \\
\hline \multirow[t]{3}{*}{ Self-care } & Day 0 & $2.65(1.03)$ & 2.21 & 3.10 & $2.91(0.77)$ & 2.56 & 3.26 & 0.408 \\
\hline & Day 56 & $2.96(0.88)$ & 2.58 & 3.34 & $\mathrm{I} .62(0.8 \mathrm{I})$ & 1.25 & 1.99 & $<0.001$ \\
\hline & $\mathrm{P}^{* *}$ & \multicolumn{3}{|l|}{0.117} & \multicolumn{3}{|l|}{$<0.001$} & \\
\hline \multirow[t]{3}{*}{ Daily Activities } & Day 0 & $3.48(0.90)$ & 3.09 & 3.87 & $3.48(0.99)$ & 3.03 & 3.92 & 0.786 \\
\hline & Day 56 & $3.39(1.03)$ & 2.95 & 3.84 & $1.86(0.66)$ & 1.56 & 2.16 & $<0.001$ \\
\hline & $\mathrm{P}^{* *}$ & \multicolumn{3}{|l|}{0.691} & \multicolumn{3}{|l|}{$<0.001$} & \\
\hline \multirow[t]{3}{*}{ Pain/Discomfort } & Day 0 & $3.35(0.7 I)$ & 3.04 & 3.66 & $3.67(0.97)$ & 3.23 & 4.11 & 0.213 \\
\hline & Day 56 & $3.48(1.04)$ & 3.03 & 3.93 & I.8I (0.75) & 1.47 & 2.15 & $<0.001$ \\
\hline & $\mathrm{P}^{* *}$ & \multicolumn{3}{|l|}{0.490} & \multicolumn{3}{|l|}{$<0.001$} & \\
\hline \multirow[t]{3}{*}{ Anxiety/Depression } & Day 0 & $2.35(1.07)$ & 1.89 & 2.81 & $2.57(0.87)$ & 2.18 & 2.97 & 0.459 \\
\hline & Day 56 & $2.61(0.78)$ & 2.27 & 2.95 & $1.62(0.74)$ & 1.28 & 1.96 & $<0.001$ \\
\hline & $\mathrm{P}^{* *}$ & \multicolumn{3}{|l|}{0.238} & \multicolumn{3}{|l|}{0.001} & \\
\hline \multirow[t]{3}{*}{ Total } & Day 0 & $|4.9|(2.92)$ & 13.7 & 16.2 & I5.86 (2.69) & 14.63 & 17.08 & 0.265 \\
\hline & Day 56 & $15.96(3.72)$ & 14.3 & 17.6 & $8.57(3.14)$ & 7.14 & 10.00 & $<0.001$ \\
\hline & $\mathrm{p}^{* *}$ & \multicolumn{3}{|l|}{0.141} & \multicolumn{3}{|l|}{$<0.001$} & \\
\hline
\end{tabular}

Notes: *P, Mann-Whitney U-test; **Wilcoxon signed rank test.

Abbreviation: $\mathrm{n}$, number of participants; SD, standard deviation; $\mathrm{Cl}$, confidence interval; Min, minimum; Max, maximum.

$19.6 \%$ reduction in the total WOMAC score as compared to the initial baseline values. ${ }^{27}$ Whereas, E-OA-07, during the

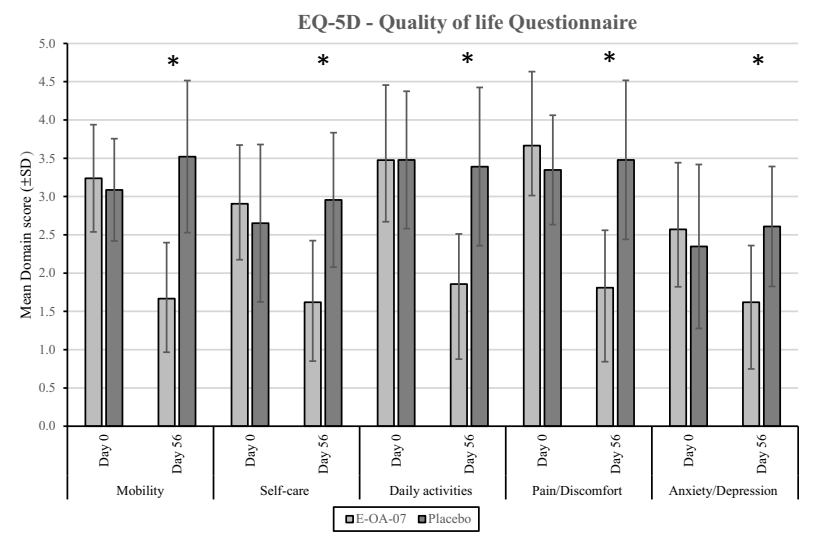

Figure 3 Quality-of-life score response to placebo and E-OA-07 therapy. Significant improvement was observed in each of the domains: mobility, self-care, daily activities, pain/discomfort, and anxiety/depression. *p $<0.001$. same period, reduced total WOMAC score by $40 \%$ despite having higher baseline scores. Additionally, the perceived improvement in Boswellia serrata group was evident only after a period of 120 days. Whereas, E-OA-07 achieved the same within 28 days of administration, thus demonstrating its strong analgesic action. In another study, Lugo and associates assessed the efficacy and tolerability of a collagen supplement in exercise-induced joint pain. Significant reduction in pain was observed after 6 months of IP administration, but with a number of side effects. ${ }^{28}$ In the present study, no adverse or serious adverse effects were reported during the 8 week study period. Overall, results of the present study support the effectiveness and safety of E-OA-07 in individuals suffering from symptoms of knee OA.

The first-ever study conducted on E-OA-07 by Kulkarni et al was inclusive of individuals of having 
Table 6 SAT Scores Evaluated At The End Of Study Period (Day 56)

\begin{tabular}{|c|c|c|c|c|c|c|c|}
\hline \multirow[t]{3}{*}{ Domains } & \multicolumn{3}{|c|}{ Placebo $(n=23)$} & \multicolumn{3}{|c|}{ E-OA-07 (n=2I) } & \multirow[t]{3}{*}{ p value* } \\
\hline & \multirow[t]{2}{*}{ Mean (SD) } & \multicolumn{2}{|c|}{$95 \% \mathrm{Cl}$} & \multirow[t]{2}{*}{ Mean (SD) } & \multicolumn{2}{|c|}{$95 \% \mathrm{Cl}$} & \\
\hline & & Min & Max & & Min & Max & \\
\hline Pain relief & $2.17(1.03)$ & 1.73 & 2.62 & $3.91(1.09)$ & 3.41 & 4.40 & $<0.001$ \\
\hline Activity levels & $2.13(0.97)$ & 1.71 & 2.55 & $3.71(1.15)$ & 3.19 & 4.24 & $<0.001$ \\
\hline Change in $\mathrm{QOL}$ & $2.52(0.95)$ & 2.11 & 2.93 & $3.91(1.14)$ & 3.39 & 4.42 & $<0.001$ \\
\hline Treatment satisfaction & $2.22(1.17)$ & 1.71 & 2.72 & $4.29(0.90)$ & 3.88 & 4.70 & $<0.001$ \\
\hline Treatment preference & $2.26(1.25)$ & 1.72 & 2.80 & $4.24(0.94)$ & 3.81 & 4.67 & $<0.001$ \\
\hline Total & $11.30(4.62)$ & 9.31 & 13.30 & $20.05(4.60)$ & 17.95 & 22.14 & $<0.001$ \\
\hline
\end{tabular}

Note: *P, Mann-Whitney U-test.

Abbreviations: $\mathrm{n}$, number of participants; $\mathrm{SD}$, standard deviation; $\mathrm{Cl}$, confidence interval; Min, minimum; Max, maximum.

Table 7 Vital Signs

\begin{tabular}{|c|c|c|c|c|c|c|}
\hline \multirow[t]{3}{*}{ Visits } & \multicolumn{3}{|c|}{ Placebo $(n=23)$} & \multicolumn{3}{|c|}{ E-OA-07 $(n=2 I)$} \\
\hline & \multirow[t]{2}{*}{ Mean (SD) } & \multicolumn{2}{|c|}{$95 \% \mathrm{Cl}$} & \multirow[t]{2}{*}{ Mean (SD) } & \multicolumn{2}{|c|}{$95 \% \mathrm{Cl}$} \\
\hline & & Min & Max & & Min & Max \\
\hline \multicolumn{7}{|c|}{ Pulse Rate } \\
\hline Day 0 & $87.57(9.24)$ & 68 & 100 & $82.38(9.78)$ & 61 & 98 \\
\hline Day 56 & $80.04(8.85)$ & 65 & 98 & $80.29(8.22)$ & 62 & 97 \\
\hline P value* & \multicolumn{3}{|l|}{0.003} & \multicolumn{3}{|l|}{0.556} \\
\hline \multicolumn{7}{|c|}{ Systolic blood pressure } \\
\hline Day 0 & I22.48 (7.52) & 110 & 134 & |23.7| (7.46) & 110 & 130 \\
\hline Day 56 & I20.87 (7.33) & 110 & 130 & $122.14(6.8 I)$ & 110 & 130 \\
\hline P value* & \multicolumn{3}{|l|}{0.622} & \multicolumn{3}{|l|}{0.236} \\
\hline \multicolumn{7}{|c|}{ Diastolic Blood Pressure } \\
\hline Day 0 & $80.30(6.04)$ & 70 & 90 & $79.10(7.22)$ & 70 & 90 \\
\hline Day 56 & $77.39(7.52)$ & 70 & 90 & $77.62(7.68)$ & 70 & 90 \\
\hline P value* & \multicolumn{3}{|l|}{0.102} & \multicolumn{3}{|l|}{0.465} \\
\hline
\end{tabular}

Note: *P, Wilcoxon Signed Rank test.

Abbreviations: $\mathrm{n}$, number of participants; SD, standard deviation; $\mathrm{Cl}$, confidence interval; Min, minimum; Max, maximum.

grade III chronic knee OA as per the K\&L scale. ${ }^{14}$ The study showed an $\sim 50 \%$ reduction in the WOMAC pain scale which is similar to the results observed in the present study, but at a significantly lower dose. This implies that the lower dose of $1000 \mathrm{mg} /$ day is as effective as the previously studied dose of $2700 \mathrm{mg}$ /day. Our second study by Girandola and associates recruited healthier individuals conforming to radiographic conditioning of $\mathrm{K} \& \mathrm{~L}$ grade I/II. E-OA-07 was compared with ibuprofen for assessing the degree of relief experienced by study participants in activity-induced joint pain. Clinically meaningful relief was experienced by the participants within 3 hrs of E-OA-07 administration. ${ }^{15}$ This potent analgesic action of E-OA-07 was consistent across both studies even though the trial designs, study population, duration and objectives of Girandola's research and ours were completely different. Also, by using healthier population and non-disease endpoints as efficacy measures, we believe that the analgesic action of E-OA-07 can also be applicable to younger or middle-aged adult population.

Research indicates that severe joint pain limits a person's ability to perform ordinary day-to-day tasks. This 
Table 8 Hematological And Biochemical Parameters

\begin{tabular}{|c|c|c|c|c|c|c|}
\hline \multirow[t]{3}{*}{ Visits } & \multicolumn{3}{|l|}{ Placebo $(n=23)$} & \multicolumn{3}{|l|}{ E-OA-07 (n=2I) } \\
\hline & \multirow[t]{2}{*}{ Mean (SD) } & \multicolumn{2}{|l|}{$95 \% \mathrm{Cl}$} & \multirow[t]{2}{*}{ Mean (SD) } & \multicolumn{2}{|l|}{$95 \% \mathrm{Cl}$} \\
\hline & & Min & Max & & Min & Max \\
\hline \multicolumn{7}{|c|}{ Hemoglobin (g/dl) } \\
\hline Day 0 & $12.50(0.92)$ & 10.9 & 15.0 & $12.95(1.66)$ & 9.6 & 16.3 \\
\hline Day 56 & $12.58(1.03)$ & $\mathrm{II} . \mathrm{I}$ & 15.1 & $13.20(1.66)$ & 10.0 & 16.4 \\
\hline $\mathrm{P}$ value* & \multicolumn{3}{|l|}{0.385} & \multicolumn{3}{|l|}{0.321} \\
\hline \multicolumn{7}{|c|}{ Red Blood Cells (RBC) Count (mil/cmm) } \\
\hline Day 0 & $4.50(0.40)$ & 3.44 & 5.20 & $4.66(0.64)$ & 3.31 & 5.97 \\
\hline Day 56 & $4.57(0.5 \mathrm{I})$ & 2.98 & 5.60 & $4.75(0.60)$ & 3.88 & 6.21 \\
\hline $\mathrm{P}$ value* & \multicolumn{3}{|l|}{0.322} & \multicolumn{3}{|l|}{0.295} \\
\hline \multicolumn{7}{|c|}{$\begin{array}{l}\text { White Blood Cells (WBC) Count (mil/ } \\
\mathrm{cmm} \text { ) }\end{array}$} \\
\hline Day 0 & $8669.57(2327.39)$ & 4900 & 12,000 & $7485.00(1401.98)$ & 4600 & 10,300 \\
\hline Day 56 & $9004.35(2779.06)$ & 5400 & 16,100 & $8352.38(1651.55)$ & 5000 & 11,200 \\
\hline$P$ value* & \multicolumn{3}{|l|}{0.685} & \multicolumn{3}{|l|}{0.036} \\
\hline \multicolumn{7}{|c|}{ Platelet Count (per cmm) } \\
\hline Day 0 & $291,086.96(68,425.08)$ & $|4|, 000$ & 467,000 & $270,350.00(72,955.12)$ & 112,000 & 455,000 \\
\hline Day 56 & $294,521.74(75,998.73)$ & 152,000 & 403,000 & $275,380.95(63,242.77)$ & 128,000 & 354,000 \\
\hline$P$ value* & \multicolumn{3}{|l|}{0.194} & \multicolumn{3}{|l|}{0.668} \\
\hline \multicolumn{7}{|c|}{$\begin{array}{l}\text { Serum Glutamic-Oxaloacetic } \\
\text { Transaminase (SGOT)(U/L) }\end{array}$} \\
\hline Day 0 & $19.64(6.87)$ & 9.8 & 37.8 & $20.15(7.26)$ & 12.1 & 44.9 \\
\hline Day 56 & $20.87(7.52)$ & 10.1 & 36.2 & $21.71(7.74)$ & 13.9 & 43.2 \\
\hline $\mathrm{P}$ value* & \multicolumn{3}{|l|}{0.354} & \multicolumn{3}{|l|}{0.651} \\
\hline \multicolumn{7}{|c|}{$\begin{array}{l}\text { Serum Glutamic-Pyruvic Transaminase } \\
\text { (SGPT) (U/L) }\end{array}$} \\
\hline Day 0 & $19.02(9.10)$ & 8.9 & 45.2 & $19.12(9.31)$ & 5.5 & 35.8 \\
\hline Day 56 & $19.35(8.77)$ & 8.9 & 42.1 & $20.47(9.74)$ & 9.1 & 40.7 \\
\hline$P$ value* & \multicolumn{3}{|l|}{0.495} & \multicolumn{3}{|l|}{0.958} \\
\hline \multicolumn{7}{|c|}{$\begin{array}{l}\text { High sensitivity C-Reactive Protein (hs- } \\
\text { CRP) }\end{array}$} \\
\hline Day 0 & $3.79(3.43)$ & 2.31 & 5.27 & $3.18(2.86)$ & 1.88 & 4.48 \\
\hline Day 56 & 4.65 (6.09) & 2.02 & 7.29 & $3.86(4.00)$ & 2.04 & 5.68 \\
\hline$P$ value* & \multicolumn{3}{|l|}{0.438} & \multicolumn{3}{|l|}{0.455} \\
\hline
\end{tabular}

Note: *P, Wilcoxon Signed Rank test.

Abbreviations: $\mathrm{n}$, number of participants; SD, standard deviation; $\mathrm{Cl}$, confidence interval; Min, minimum and Max, maximum. 
affects their QoL as greater the pain severity, poorer is the corresponding QoL. ${ }^{29}$ In the present study, we utilized EQ-5D questionnaire for measuring hr-QoL in participants with moderate-to-severe cases of knee OA. At the end of the study, majority of E-OA-07 participants had their QoL improved, and a clear pattern of improvement was observed in each of the EQ-5D domains. Additionally, these improvements led to better treatment satisfaction in E-OA-07 participants reporting higher SAT scores as compared to the placebo group. Therefore, results of the present study show that E-OA-07 bettered QoL by reducing pain intensity, which in turn raised the treatment satisfaction of study participants.

Elevated levels of hs-CRP have been correlated with OA disease progression and also with symptoms of pain and stiffness. ${ }^{30}$ However, the relationship between inflammatory markers and knee OA still remains controversial topic due to contradictory findings. ${ }^{31}$ In a recent metaanalysis, only fish oil was able to significantly reduce hsCRP levels, whereas botanicals such as garlic, ginseng, saw palmetto, and pycnogenol-containing supplements failed to induce any changes. In the present study, there was no significant change observed in the hs-CRP levels of study participants. ${ }^{32}$ We believe this lack of effect can possibly be attributed to the presence of confounding factors such as obesity, ${ }^{33}$ asymptomatic viral or bacterial infection ${ }^{34}$ or age-related cardiovascular fatigue ${ }^{35}$ in the present study population. Longer duration studies may be required to ascertain the same.

Two of the most frequent causes of non-compliant behavior are misunderstanding of dosage regimens and the cost borne by the consumer. ${ }^{36}$ A lifelong compliance to a variety of regimens ultimately influences health-care costs. This is particularly of importance in individuals with repeated and overuse of joints, as they are at greatest risk for chronic conditions. If there was a way to manage this, not only the level of compliance would be improved but also the consumer costs would be lessened. In the present study, the efficacy of E-OA-07 on a reduced dose was approved and improvement in each of the efficacy variables was significantly superior to the placebo group. Also, results are further consolidated by the excellent safety and tolerability profile demonstrated by E-OA-07 in clinical as well as laboratory parameters. All these attributes can certainly have beneficial effects in terms of efficacy, compliance and cost-effectiveness. However, there is a potential limitation to the present study. There were no statistically significant changes observed in the hs-CRP marker between the groups or within the groups. Future studies can be attempted to explore the effect of E-OA-07 on hs-CRP, preconditioned to a larger but homogenized set of population with fewer confounding variables.

\section{Conclusion}

E-OA-07 at a dose of $1000 \mathrm{mg} /$ day was able to significantly reduce joint pain, and thereby improve joint mobility in study participants. At the end of the study period, there was a clinically relevant change of $45.55 \%, 45.91 \%$ and $38.19 \%$ for pain, stiffness and physical function, respectively. Moving forward, studies could be planned for understanding the cartilage regenerative properties of E-OA-07.

\section{Abbreviations}

WOMAC, Western Ontario and McMaster Universities Osteoarthritis Index; EQ-5D-5L, European quality of life5 dimensions-5 levels; NSAIDs, nonsteroidal anti-inflammatory drugs; OA, osteoarthritis; IEC, independent ethics committee; BMI, body mass index; VAS, visual analogue scale; K\&L, Kellgren and Lawrence; SAT, self-assessment of treatment; hs-CRP, high-sensitivity C-reactive protein; ICH-GCP, International council of harmonisation - good clinical practice; ANOVA, analysis of variance; SPSS, statistical package for the social sciences; SD, standard deviation; CI, confidence interval; QoL, quality of life; $\mathrm{RBC}$, red blood corpuscle; WBC, white blood corpuscle; SGOT, serum glutamic oxaloacetic transaminase; SGPT, serum glutamic pyruvic transaminase.

\section{Data Sharing Statement}

The datasets used and/or analyzed during the current study are available on a reasonable request from the authors.

\section{Acknowledgements}

We would like to acknowledge the financial support by Enovate Biolife, operational and quality management by Vedic Lifesciences and Dr. Sagar Karvir for his role as principal investigator on the study.

\section{Disclosure}

Dr. Shalini Srivastava and Mr. Jayesh A Chaudhary are affiliated to Enovate Biolife and Vedic Lifesciences. The authors report no other conflicts of interest in this work. 


\section{References}

1. Mobasheri A. The future of osteoarthritis therapeutics: targeted pharmacological therapy. Curr Rheumatol Rep. 2013;15(10):364. doi:10. 1007/s11926-013-0364-9

2. Zhang W, Ouyang H, Dass CR, Xu J. Current research on pharmacologic and regenerative therapies for osteoarthritis. Bone Res. 2016;4:15040. doi:10.1038/boneres.2015.40

3. U. S. Food and Drug Administration. Center for Drug Evaluation and Research. FDA strengthens warning that non-aspirin nonsteroidal anti-inflammatory drugs (NSAIDs) can cause heart attacks or strokes: FDA Drug Safety Communication; 2015. https://www.fda.gov/drugs/ drug-safety-and-availability/fda-drug-safety-communication-fdastrengthens-warning-non-aspirin-nonsteroidal-anti-inflammatory.

4. Yocum D, Fleischmann R, Dalgin P, Caldwell J, Hall D, Roszko P. Safety and efficacy of meloxicam in the treatment of osteoarthritis: a 12Week, double-blind, multiple-dose, placebo-controlled trial. Arch Intern Med. 2000;160(19):2947-2954. doi:10.1001/archinte.160.19.2947

5. Hawker GA, White D, Skou ST. Non-pharmacological management of osteoarthritis. Osteoarthritis Cartilage. 2017;25(1):S4. doi:10.10 16/j.joca.2017.02.013

6. Villafañe JH. Exercise and osteoarthritis: an update. J Exerc Rehabil. 2018;14(4):538-539. doi:10.12965/jer.1836352.176

7. Szychlinska MA, Castrogiovanni P, Trovato FM, et al. Physical activity and Mediterranean diet based on olive tree phenolic compounds from two different geographical areas have protective effects on early osteoarthritis, muscle atrophy and hepatic steatosis. Eur $J$ Nutr. 2019;58(2):565-581. doi:10.1007/s00394-018-1632-2

8. Castrogiovanni P, Di Rosa M, Ravalli S, et al. Moderate physical activity as a prevention method for knee osteoarthritis and the role of synoviocytes as biological key. Int J Mol Sci. 2019;20(3):511. doi:10.3390/ijms20030511

9. Ambrose KR, Golightly YM. Physical exercise as non-pharmacological treatment of chronic pain: why and when. Best Pract Res Clin Rheumatol. 2015;29(1):120-130. doi:10.1016/j.berh.2015.04.022

10. Leach MJ, Kumar S. The clinical effectiveness of Ginger (Zingiber officinale) in adults with osteoarthritis. Int $J$ Evid Based Healthc. 2008;6(3):311-320. doi:10.1111/j.1744-1609.2008.00106.x

11. Bartels EM, Folmer VN, Bliddal H, et al. Efficacy and safety of ginger in osteoarthritis patients: a meta-analysis of randomized placebo-controlled trials. Osteoarthritis Cartilage. 2015;23(1):13-21. doi:10.1016/j.joca.2014.09.024

12. Haroyan A, Mukuchyan V, Mkrtchyan N, et al. Efficacy and safety of curcumin and its combination with boswellic acid in osteoarthritis: a comparative, randomized, double-blind, placebo-controlled study. BMC Complement Altern Med. 2018;18(1):7. doi:10.1186/s12906017-2062-z

13. Daily JW, Yang M, Park S. Efficacy of turmeric extracts and curcumin for alleviating the symptoms of joint arthritis: a systematic review and meta-analysis of randomized clinical trials. J Med Food. 2016;19(8):717-729. doi:10.1089/jmf.2016.3705

14. Kulkarni MP, Shakeel A, Shinde BS, Rosenbloom RA. Efficacy and safety of E-OA-07 in moderate to severe symptoms of osteoarthritis: a double-blind randomized placebo-controlled study. Am $J$ Ther. 2011;18(2):170-177. doi:10.1097/MJT.0b013e318209df49

15. Girandola RN, Srivastava S, Loullis CC. A clinical trial comparing Lanconone ${ }^{\circledR}$ with ibuprofen for rapid relief in acute joint pain. Trials. 2016;17:189. doi:10.1186/s13063-016-1268-6

16. Kohn MD, Sassoon AA, Fernando ND. Classifications in brief: Kellgren-Lawrence classification of osteoarthritis. Clin Orthop Relat Res. 2016;474(8):1886-1893. doi:10.1007/s11999-016-4732-4

17. Chopra A, Lavin P, Patwardhan B, Chitre D. Randomized double blind trial of an ayurvedic plant derived formulation for treatment of rheumatoid arthritis. J Rheumatol. 2000;27(6):1365-1372. PMID: 10852255
18. EuroQol Group. EuroQol-a new facility for the measurement of health related quality of life. Hlth Pol. 1990;16:199-208. doi:10. 1016/0168-8510(90)90421-9

19. Herdman M, Gudex C, Lloyd A, et al. Development and preliminary testing of the new five-level version of EQ-5D (EQ-5D-5L). Qual Life Res. 2011;20(10):1727-1736. doi:10.1007/s11136-0119903-x

20. Wyrwich KW, Kawata AK, Thompson C, Holmstrom S, Stoker M, Wiklund I. Validation of the self-assessment of treatment questionnaire among patients with postherpetic neuralgia. Pain Res Treat. 2012;2012:621619. doi:10.1155/2012/621619

21. Stürmer T, Brenner H, Koenig W, Günther KP. Severity and extent of osteoarthritis and low grade systemic inflammation as assessed by high sensitivity C reactive protein. Ann Rheum Dis. 2004;63(2):200205. doi:10.1136/ard.2003.007674

22. Bonnet CS, Walsh DA. Osteoarthritis, angiogenesis and inflammation. Rheumatology. 2005;44(1):7-16. doi:10.1093/rheumatology/keh344

23. Castrogiovanni P, Trovato FM, Loreto C, Nsir H, Szychlinska MA, Musumeci G. Nutraceutical supplements in the management and prevention of osteoarthritis. Int J Mol Sci. 2016;17(12):2042. doi:10.3390/ijms17122042

24. Ha CW, Park YB, Min BW, et al. Prospective, randomized, doubleblinded, double-dummy and multicenter phase IV clinical study comparing the efficacy and safety of PG201 (Layla) and SKI306X in patients with osteoarthritis. $J$ Ethnopharmacol. 2016;181:1-7. doi:10.1016/j.jep.2016.01.029

25. Park YG, Ha CW, Han CD, et al. A prospective, randomized, doubleblind, multicenter comparative study on the safety and efficacy of Celecoxib and GCSB-5, dried extracts of six herbs, for the treatment of osteoarthritis of knee joint. J Ethnopharmacol. 2013;149(3):816824. doi:10.1016/j.jep.2013.08.008

26. Wang A, Leong DJ, Cardoso L, Sun HB. Nutraceuticals and osteoarthritis pain. Pharmacol Ther. 2018;187:167-179. doi:10.1016/j. pharmthera.2018.02.015

27. Majeed M, Majeed S, Narayanan NK, Nagabhushanam K. A pilot, randomized, double-blind, placebo-controlled trial to assess the safety and efficacy of a novel Boswellia serrata extract in the management of osteoarthritis of the knee. Phytother Res. 2019;33 (5):1457-1468. doi:10.1002/ptr.6338

28. Lugo JP, Saiyed ZM, Lane NE. Efficacy and tolerability of an undenatured type II collagen supplement in modulating knee osteoarthritis symptoms: a multicenter randomized, double-blind, placebocontrolled study. Nutr J. 2016;15:14. doi:10.1186/s12937-016-0130-8

29. Dueñas M, Ojeda B, Salazar A, Mico JA, Failde I. A review of chronic pain impact on patients, their social environment and the health care system. J Pain Res. 2016;9:457-467. doi:10.2147/JPR. S105892

30. Smith JW, Martins TB, Gopez E, Johnson T, Hill HR, Rosenberg TD. Significance of C-reactive protein in osteoarthritis and total knee arthroplasty outcomes. Ther Adv Musculoskelet Dis. 2012;4(5):315325. doi:10.1177/1759720X12455959

31. Barbe MF, Barr AE. Inflammation and the pathophysiology of workrelated musculoskeletal disorders. Brain Behav Immun. 2006;20 (5):423-429. doi:10.1016/j.bbi.2006.03.001

32. Zhang J. Meta-analysis of serum C-reactive protein and cartilage oligomeric matrix protein levels as biomarkers for clinical knee osteoarthritis. BMC Musculoskelet Disord. 2018;19(1):22. doi:10.1186/s12891-0181932-y

33. Czarnywojtek A, Owecki M, Zgorzalewicz-Stachowiak M, et al. The role of serum C-reactive protein measured by high-sensitive method in thyroid disease. Arch Immunol Ther Exp (Warsz). 2014;62(6):501509. doi:10.1007/s00005-014-0282-1

34. Kolb-Bachofen V. A review on the biological properties of C-reactive protein. Immunobiology. 1991;183(1-2):133-145. doi:10.1016/S01 71-2985(11)80193-2 
35. Che W, Zhang B, Liu W, Wei Y, Xu Y, Hu D. Association between high-sensitivity $\mathrm{C}$-reactive protein and N-Terminal Pro-B-Type natriuretic peptide in patients with hepatitis $\mathrm{C}$ virus infection. Mediators Inflamm. 2012;2012:730923. doi:10.1155/2012/730923
36. Jin J, Sklar GE, Min Sen Oh V, Chuen, Li S. Factors affecting therapeutic compliance: a review from the patient's perspective. Ther Clin Risk Manag. 2008;4(1):269-286. doi:10.2147/tcrm.s1458

\section{Publish your work in this journal}

The Journal of Pain Research is an international, peer reviewed, open access, online journal that welcomes laboratory and clinical findings in the fields of pain research and the prevention and management of pain. Original research, reviews, symposium reports, hypothesis formation and commentaries are all considered for publication. The manuscript

Submit your manuscript here: https://www.dovepress.com/journal-of-pain-research-journal management system is completely online and includes a very quick and fair peer-review system, which is all easy to use. Visit http:// www.dovepress.com/testimonials.php to read real quotes from published authors. 